\title{
THE SEMIOLOGY OF CHANGING BRAND IMAGE
}

Ian Combe, University of North London, UK

David Crowther, University of North London, $U K$

Steve Greenland, University of North London, UK

\begin{abstract}
This article considers the attempted change to the image of an established brand by studying the semiotics within the brand's historical advertising campaigns. The use of semiotics to study the interpretation of messages is discussed, and the link between interpretation of messages and advertising effectiveness in changing brand image is explored. The authors deconstruct advertisements of a brand to provide a model containing opposing dialectics that may aid managers by highlighting alternative symbolic messages contained in advertisements. Once identified, these alternative symbolic messages may be used to help change brand image and influence advertising effectiveness.
\end{abstract}

\section{Key Words:}

Semiotics

Dialectics

Branding

Advertising Messages

Interpretation

\section{Address for correspondence:}

Ian Combe

The Business School,

University of North London,

Stapleton House,

277 - 281 Holloway Road,

London N7 8HN

Tel: 02076072789

email: i.combe@unl.ac.uk 


\title{
THE SEMIOLOGY OF CHANGING BRAND IMAGE
}

\begin{abstract}
This article considers the attempted change to the image of an established brand by studying the semiotics within the brand's historical advertising campaigns. The use of semiotics to study the interpretation of messages is discussed, and the link between interpretation of messages and advertising effectiveness in changing brand image is explored. The authors deconstruct advertisements of a brand to provide a model containing opposing dialectics that may aid managers by highlighting alternative symbolic messages contained in advertisements. Once identified, these alternative symbolic messages may be used to help change brand image and influence advertising effectiveness.
\end{abstract}




\section{THE SEMIOLOGY OF CHANGING BRAND IMAGE}

\section{INTRODUCTION}

The symbolic metaphor of communications suggests that communications function as a creation, maintenance and transformation of meanings (Bantz, 1993; Carey, 1989; Putnam, Philips, \& Chapman, 1996). Advertising in this context is important for the communication of symbols, in which a symbol is something that stands for or suggests something else through association or convention (Saussure, 1966). The meaning of a symbol is typically rooted in cultural significance (Thompson, Pollio \& Locander, 1994), and communication is interpretation through the production of symbols that make the world meaningful (Putnam, Philips \& Chapman, 1996).

The effectiveness of advertising in changing the image of a brand in the mind of the consumer will therefore depend on the symbolic interpretation of the advertised message by the recipients of the message. However, models to help managers understand symbolic interpretations to enable them to change brand image seem to be lacking. In this article this important issue is addressed. The authors use dialectics ${ }^{1}$ to deconstruct (see Elliott, 1997) an exemplar advertisement to highlight some of the possible signs and symbols underlying an attempted change in brand image. The use of this device is consistent with those researchers who conceptualize image, or in this case brand image, as a 'narrative' (e.g. Askegaard \& Ger, 1998; Christensen \& Askegaard, 2001) and is used to develop an historical model (before and after the change) of the semiology of changing brand image. This model may be useful to managers involved in changing brand image, because many of the dialectics used have cultural significance and can therefore be applied to other advertisements, especially those targeted at the same cultural groups.

To develop the semiology of changing brand image in this article a background to semiotics (see also Barley, 1983) and the construction of social identity through consumption is briefly discussed (see also Elliott \& Wattanasuwan, 1998; and Firat, Dholakia \& Venkatesh, 1995). An understanding of these issues is necessary because they impact on the interpretation of signs and symbols within advertising messages and hence how the brand is perceived by consumers. Changing brand image is then discussed by reference to an exemplar case Murphy's beer that has undertaken an advertising campaign to change the image of the brand. The historical advertisements for Murphy's beer advertisements are used to highlight alternative semiotics, some of which were expressly used by the company to help change its brand image.

\section{BACKGROUND TO SEMIOLOGY}

The roots of semiology or semiotics stem from two distinct strands of literature - the linguistic work of Saussure (1966) and the philosophical work of Pierce (1958). Each source leads to a slightly different mode of analysis. Saussure (1966) identified a sign as a dyadic, having two sides: the signifier and the signified, which were considered inseparable. The signifier being the material object and the signified being its associated mental concept. Thus Saussure's (1966) understanding of the process of communication is based upon an assumption of the transfer of mental concepts through the signs produced. Pierce (1958), on the other hand developed a triadic theory of the signs based upon the triple relationship of the representamen, the object and the interpretant. In his theory the representamen is the sign itself, the object is that which the representamen stands for and the interpretant is the significate effect of the sign.

Saussurian semiology must necessarily be undertaken in the context of a wider system of 
meaning external to the sign itself. In this mode of analysis the sign itself is part of a flow of meaning and is interpreted contextually and individually by each individual participating in the communication event. Piercian semiotics on the other hand functions on the basis that each sign is self-contained and able to generate further signs, with associated meanings, from within itself. Thus the Piercian approach has its own internal dynamic associated with both the sign and its interpretation which is often referred to as an unlimited semiosis. Pierce's system of semiotics has been extensively critiqued by Habermas (1971) because of his assumption that every individual is able to produce his own semiotic from the communication event. Thus the semiotic can be viewed as infinitely variable, because any event would not produce the same semiotic for each individual.

For static signs, such as advertisements, this Peircian method of semiotic analysis provides a suitable method of interpretation and understanding of meaning. For the advertising under consideration in this article, however, the sign is not static but is contextual to the audience and their environment. Thus the advertisement produces not just one sign but rather a multiplicity of signs each of which are contextually dependant upon the other signs produced. It is for this reason that Saussurian methodology is considered to be the most appropriate method of analysis and is used in this article.

The semiology of Saussure has been developed extensively by later writers. One significant analysis has been undertaken by Lacan (1977) who argued that human being are entirely enmeshed within the sign and its subjectivity thereby making the separation of the signifier and the signified impossible. Lacan (1977) developed these arguments further in the context of his psychoanalysis, but this inextricable enmeshment of the person as an individual within the semiotic of any sign provides a starting point for an understanding of the semiology of an advertising campaign.

Semiotics, or semiology - the two terms are interchangeable - has been defined simply as 'the study of signs' (Guiraud, 1975). This description however must be viewed as being overly simplistic. A more comprehensive interpretation suggests that semiotics is the study of the creation of the symbolic and its subsequent signification. Thus semiology has been further defined as 'a science which studies the life of signs within society' (Saussure, 1966). Semiotics can therefore be considered to be a study of communication and more particularly the study of communication acts or events - a study of the message itself and its relationship with the recipient of that message.

\section{Communication and Semiotics}

From a semiotic perspective, communication is determined by the interrelationship between the message itself and the recipient of that message. In this respect therefore, as Derrida (1978) argues, the writer of the message ceases to have any significance once the message has been written, as interpretation is entirely determined by this interplay between the message and its recipient. In other words meaning is in the interpretation of the message by the recipient and the intentions of the writer are therefore irrelevant. This inevitably places a heavy burden upon the recipient of the message in extracting meaning from that message but it also places a heavy burden upon the writer of the message. Thus, rather than being irrelevant to the message, the writer of the message is in fact central to the message itself as (s)he must endeavour to ensure that the meaning wished to be imparted is actually the one which is extracted by the recipient rather than any alternative meaning.

In spoken communication this is a relatively simple exercise as the speaker knows something about the hearer, has a general understanding of the context in which the communication is being made, and receives feedback which enables the message to be modified during its 
transmission. However, when the message is transmitted in written or visual form the situation is very different, because there is no framing context for the message, or rather there is a different framing context for each reader or viewer. There is no relationship between the writer and the reader other than the message itself. Therefore, the message itself becomes the sole form of mediation between the writer and the reader or viewer and thereby assumes the dominant role in the communication. This message, therefore, becomes the totality of the communication act and the communication event becomes the relationship between the message and the reader or viewer of the message. Semiotics is the study of both the communication act and the communication event.

\section{THE CONSTRUCTION OF IDENTITY}

The consumption of alcoholic drink has historically been a social event occurring in public houses, bars, restaurants and clubs, thus reinforcing group identity. Sharing food and drink becomes a symbolic way of sharing group identity (Belk, 1988).

The construction of social identity through styles of consumption and membership of neotribes has been discussed by Bauman (1990) and has been extended into the marketing arena (e.g. Cova, 1997). The consumer may exercise choice through consumption and take on the identity symbols of the tribe by buying into tribe-specific artefacts. In the context of changing the brand image, companies therefore need to change the neo-tribe symbols and tribe-specific artefacts that are associated with the brand. This can be achieved by identity cues such as signs and symbols within advertising and the production of promotional artefacts associated with the advertisement. The effectiveness of changing the brand image will depend on the symbols chosen to be included within the advertisements and how these symbols are interpreted by the audience.

The question as to whether the tribes already exist or are in some way modified or even created through advertising and consumption is a difficult one to answer. In practice the most helpful definition of a tribe in this context is more concerned with a sense of belonging through attracting the same attributes as the tribal group to which one aspires. This is reflected in the consumption of the correct cultural symbols of the tribe to signal a belonging to that tribe. In this respect, therefore, one of the purposes of changing the brand image is to signal the tribal attributes considered appropriate for the market segment which is being targeted.

\section{THE SEMIOLOGY OF CHANGING BRAND IMAGE}

Brand image and its importance have been discussed by many writers (e.g. Aaker, 1992; Kapferer, 1992; Keller, 1993; Nebenzahl \& Jaffe, 1996; Meenaghan, 1995). Some problems are evident in this body of work. One problem is that research into image often implies a clear distinction between functional qualities of a product and its image qualities, and furthermore in relation to brand image, a distinction between the product and the more ephemeral brand. These distinctions, however, break down from a semiotic perspective (see Christensen \& Askegaard, 2001), because the functional and symbolic are inter-related. Another problem is that of trying to conceptualize the image concept. What is an image? Brand image, for example, has been defined as a set of beliefs (Kotler, 1988) or a set of associations usually organized in some meaningful way (Aaker, 1992). Such definitions of image may be in part responsible for a bias in the direction of research into the image concept. The image concept has received much attention through the study of information processing within consumer behaviour, but is typically only linked to memory or visual phenomenon rather than imagination (Christensen \& Askegaard, 2001). Attempts to study 
image from a semiotic perspective try to redress this bias to mainly cognitive understandings and attempt to overcome what can be seen as a limited conceptualization of the image concept. Some writers such as Askegaard and Ger (1998) and Christensen and Askegaard (2001) have tried to re-conceptualize the image concept by thinking of an image as a narrative that should be open to interpretive analysis to provide further understandings. Such an interpretive analysis is presented below through the use of semiotics to gain insights into an attempted change in brand image.

Changing the brand image is not necessarily concerned with highlighting a distinctive feature of the product that has changed, but is rather focused on changing the perception of the brand by consumers. This is achieved through the creation of a semiotic of the product by producing different symbols that hopefully differentiate it from the previous image. After all, the previous image is largely there due to convention, sometimes due to previous advertising. In particular when considering Murphy's beer it is important to recognise that the product is differentiated from its nearest competitor, Guinness, almost entirely by the images attached to the product - in other words by its semiotic, rather than inherent features of the product. Therefore, symbolic images of the brand are particularly important in this case.

\section{ADVERTISING TO CHANGE THE BRAND IMAGE}

A semiological view of changing brand image through advertising places the intended recipient of the advertising message at the centre of understanding, while at the same time recognising that each individual may interpret the message in a different way from other individuals. This individuality is achieved because each interpretation is personal, based upon the context - at the same time spatial, societal and temporal - of that individual. Semiology therefore recognises, and provides a framework for developing the need on the part of the advertiser to frame his/her advertising in such a way that the intended message is extracted from the campaign by as great a part of the target audience as possible. Such an understanding can therefore help increase the effectiveness of an advertising campaign.

Occasionally a leading brand of a consumer comestible seeks to change its image and this presents an opportunity to study the semiotics for an already established brand so that the steps in the process of potential change may be discovered. As such, a study of the event will lead towards the development of a semiology of changing brand image. In the context of this paper semiology is defined in the Saussurian sense of the study of the life of signs in society - in other words a study of the message event and its relationship with the recipient of that message. The understanding of the semiology of advertising in the context of changing the brand image, developed in this article, is important for an understanding of the effectiveness of advertising in this context. Such a campaign to help change the brand image has been undertaken by the Murphy's brand of beer. This campaign provides the means used in this article for developing a semiotic understanding of the potential change in the brand image.

\section{An Exemplar Advertising Campaign - Murphy's brand of beer}

To investigate the semiology of changing brand image through a study of an historical advertising campaign, two views of the change in brand image need to be investigated. Firstly, from the company's perspective (Whitbread plc) to investigate the intended change in image and intended messages built into the advertisements. The company's perspective was achieved through one of the authors attending a presentation on the brand change given by the brand manager and two follow up in-depth interviews together with the study of documentary evidence. Secondly, from the recipients of the message. The recipients perspective was obtained from written feedback from 102 business school undergraduate students of the same age as the intended target group. This feedback was conducted following 
the presentation of the historical advertisements of Murphy's beer.

Additionally, to add depth to the symbolic analysis presented by both the company and the target market, the authors raise other dialectic interpretations based on academic literature. The deconstruction of the Murphy's advertisements is undertaken to highlight some of the alternative images present in the advertisements and to draw inferences concerning the semiology of changing brand image.

The Murphy's campaign was used due to the access of information relating to brand management so that the management perspective could be evaluated. Thus the rationale for changing the brand image, the decisions relating to what to change and include in the new advertisements and the aims and objectives from the management's point of view were all available to the researcher. The campaign was also a potentially major change in brand image for the company, and represents a high profile campaign familiar to many readers.

\section{BACKGROUND TO THE CHANGING THE BRAND IMAGE OF MURPHY'S}

Murphy's Irish stout is dark beer similar to Guinness, for which it has largely been considered as a substitute. It has historically been seen to represent a traditional stout largely consumed by the older generation. However, since 1988 the reputation of Murphy's has been changing to become more popular with younger consumers and thus taken the second position in the stout market behind Guinness (Murphy's approx. 14\% versus Guinness approx. 80\%). In deconstructing the historical advertising campaigns two examples are taken: one major campaign which was last used in 1997 and the new campaign which commenced in 1998, both of which were used for television and cinema advertising.

According to the brand manager of Murphy's, the first campaign focused on "a differentiation of Murphy's within the stout market against Guinness and positioned Murphy's as easy going" based on its milder taste. It also focused on trying to convince traditional bitter drinkers to switch to this milder taste. This campaign therefore highlighted a traditional country Irish pub with both young and old clientele with the strap-line "Unlike the Murphy's, he's very bitter":

\section{take in Plate 1}

This successful campaign ran for many years. However, during the last two years of this campaign (1996 and 1997) Murphy's had experienced a downward trend in sales. According to the management, the brand was being seen as a "repertoire drink" and therefore only drunk occasionally. This combined with increasing competition due to the widespread introduction of creamy beers such as Caffreys led to a serious sales decline.

To conceive a new advertising campaign the management had to identify the problems with their present campaign. Thus meetings of the management team explored how the brand was portrayed in the current (old) campaign and how the management wished the brand to be portrayed in future. Due to the poor sales figures "all images were up for revision". The following major decisions were made:

- To not necessarily depend on being Irish - The management team decided to retain the Irish connection but wished to be associated with modern city Ireland rather than country Ireland

- To portray images that would appeal to a younger mainly male market - "Power in a black pint"

- To overcome and refine being black - blind tastings suggested that the colour influenced 
perceptions, such as the perception that Murphy's is a "heavy" drink

This resulted in a new campaign based upon the Sisters of Murphy advertising:

take in Plate 2

Apart from the television and cinema advertising the campaign included a variety of special events in pubs including several groups of actors posing as the Sisters of Murphy and visiting a wide variety of such pubs.

The results of these decisions can be explored by a comparison of the old and new advertising campaigns. To undertake this task we explore the dialectics within the Murphy's advertisements to highlight the differentiation of the old position of the brand with the new position.

\section{EXPLORING DIALECTICS WITHIN THE MURPHYS ADVERTISEMENTS}

Binary oppositions exist in every text in a synchronic manner (Kim, 1996). A consequence of this is that the binarism of diachronicity exists as the counterpart of synchronicity. Synchronicity refers to the timelessness of the text and provides a way for examination of recurring themes within the text. In such manner the campaign concerned seeks to signal the temporal independence of the text (and the product it represents) and the presentation of an image of the product as a contiguous atemporal whole. Diachronicity, on the other hand, refers to the constituent elements of the text which unfold temporally as time progresses. Diachronicity in the context of an advertising campaign tends to based upon a reference to past activities, which are compared with the present, and implying the future of the product. This is almost always in the context of an implied progression of events which is depicted as an improvement. Thus the present is always presented as an improvement upon the past while the future is suggested to be an improvement upon the present.

Thus there is both a spatial and a temporal dimension to this binary pair. In the case of a continuing product, such as Murphy's beer however, these notions are problematic as the campaign must seek to convey the message that this is an existing, tried and tested product but that it should appeal to a different audience. Thus the previous advertising had focused on the traditional nature of the beer while the new campaign seeks to portray it as exciting and youthful. The resolution of this synchronic - diachronic nature of the semiotic gives rise to some of the dialectics inherent in the campaign.

All binary opposition seeks to polarise the text in terms of the two opposite poles but this normally is undertaken in the context of portraying one pole as good and the other as bad. This is achieved through the portrayal of the poles in a violent hierarchy (Laclan, 1990). An essential part of semiotic analysis therefore is in this depiction of the poles as desirable and undesirable. An inevitable tension therefore exists when both poles are important and mediation within the text is attempted through other means when both poles are needed to appear good.

Signification is the act of relating the signified with its signifier to create a sign (Barthes, 1973). This signification occurs not only when a sign is created but also when meaning is extracted from the sign. Meaning is not transmittable however and because of this the meaning extracted by the reader is not necessarily the same as that sent by the author. Thus a sign leaves its interpreter to supply at least a part of its meaning (Pierce, 1958). Naturally it is in the interest of the author to seek to ensure that the meaning (s)he wishes to impart through the text is the meaning extracted by the reader. As there is no direct communication in a text such as an advertisement between the author and the reader then it is in the interests of the author to seek other forms of mediation to facilitate the alignment of meanings. This is one 
reason for the use of a range of advertising techniques as a mediating mechanism as it reflects the desire on the part of the authors of campaign to bring these two signification acts into alignment.

The extraction of meaning by the reader is always contextual and is based upon the frame of reference of that reader. This frame of reference is dependant upon the experiences of the reader, as these experiences are inseparable from the script and its interpretation. The frame of reference is however partly set by the context in which the reading takes place. Thus the reading of the script of an advertising campaign is undertaken in a very different context to the reading of the script of a novel. This context is set in part by the presentation of the script itself, as the two types of script look very different. The standardisation of the components of an advertising campaign, as signalled through the main medium of television advertising, is one way of defining the context more closely in terms of that campaign. In doing so this provides a further means of closing the gap between these two significations, of the author and the reader, as this helps to create a more common frame of reference for interpretation. It is in this way that the campaign creates the desire on the part of the audience, as readers of the script, to take on cultural capital (Bourdieu, 1984), through the purchase of the product. This helps segregate the audience into those being addressed by the script and those who have access to the script but are not addressed. Thus the format of the script is determined to some extent by the demands of the audience being addressed (Metz, 1974).

Signification is therefore about inclusion within the selected audience for the campaign on the assumption that those included understand the signification in a common way with the authors. This is based upon an assumed understanding of the code of signification used in the campaign (Sapir, 1949). Thus it is comfortable for the authors of the script to assume this shared signification based upon a shared understanding of the language used. This signification is enhanced through the use of the images incorporated into the script, which add to the truth value of the information conveyed (Graves, Flesher \& Jordan, 1996), as will be considered later in this analysis. This shared signification may however be fictitious, as will also be considered later in this analysis.

To help address the complexity of different interpretations of the Murphy's advertisements and to highlight some of the intentional use of symbols by the company, we explore dialectics within the advertisements. While the use of binary oppositions is a simplified way of deconstructing the possible different interpretations within the advertisements, their use is not meant to signify that complexity can be fully encapsulated by 'either/or' responses to the eight dialectics that follow.

In the first four dialectics we discuss the competing discourses on the meaning of consumption (van Raaij, 1993). Thus we discuss Materialistic consumption versus symbolic consumption; Self consumption versus social consumption; Materialistic desire versus symbolic desire; and Social desire versus self desire, in the context of the Murphys advertisements. By use of the additional four dialectics: Male power versus female power; Cool versus uncool; Old versus young; and Country versus city, some of the main devices and symbols that the company themselves used to differentiate their new image from the image adopted in their previous advertisements are explored. Our exploratory research indicates that these images were picked up by the target audience.

\section{Materialistic consumption versus symbolic consumption}

The ultimate aim of any advertising campaign is to persuade people to purchase and consume the product concerned. However this can be made easier if the product seems to possess cultural capital, thereby becoming a desired product rather than a commodity (Featherstone, 
1991). In terms of attempting to make sense of consumerism, work by a number of commentators points to how goods can act as communicators (see for example Douglas \& Isherwood, 1980), demonstrating that their users show style and taste (Bourdieu, 1984; Featherstone, 1991). Thus for example, Nava (1997:p66) demonstrates how Edwardian women acquired such 'cultural capital' from department stores, as the 'principle source of information about the meaning of how others ...... dressed was found in the stores'.

One interpretation of post-modernism is the notion of the collapse of the difference between high culture and mass culture; such a trend was noted with considerable antipathy by the Frankfurt School. The dissolution of the difference between high and mass culture is evident in the art world, where 1960s Pop-Art not only challenged the notions of what constituted art, but also led to the spill-over of art into everyday life, through its use, inter alia, in television advertisements. Nava (1997:p57) has argued that 'there is a new stress on display and the visual', with the process being heralded, more generally, as the 'aestheticization of life'.

Thus when purchasing a pint of Murphy's beer, we are not solely buying it for 'use value' but also because of the signs and symbols attached to the product (Baudrillard, 1988). This is a point supported by Featherstone (1991) who argues that 'goods [act] as communicators not just utilities' and thereby give the emotional pleasure of consuming - not beer but rather a desirable product giving not only bodily but also aesthetic pleasure. The signs associated with consumption can be explained in terms of cultural capital having both economic and social value (Lash \& Urry, 1994). This insight into the nature of consumption has profound implications because while certain images are attached to a product, this in itself leads to the suppression of other images. Thus the changing the brand image of Murphy's to more youthful and trendy thereby suppresses the previous image of it being traditional.

\section{Self consumption versus social consumption}

Veblen (1970), coined the term 'Conspicuous Consumption', which described the way that the 'Nouveau Riche' consumed particular items in order to denote their social status. Thus the consumption of a product like Murphy's beer is more about being seen to be consuming the appropriate cultural symbol within a social setting. It is the acquisition of this cultural symbolism that imbues the product with its distinctive nature. Thus for the producer the aim is to sell its products which will then be consumed, but for the consumer the concern is not with the actual consumption but rather with the social nature of that consumption. If a good has cultural capital which is then transmitted to the user of that good then it is important to realise that this transfer of capital can only take place if it is observed - and more specifically observed by those who place the same exchange value upon that good. In this respect it is perhaps significant that Murphy's brand image campaign is focussed upon the consumption of its product in public places, rather than merely upon its consumption.

This issue has important advertising ramifications for breweries producing tinned and bottled products for consumption at home in non-public places. How much does the social image of the new advertisements influence the desire to consume at home? Addressing this issue, however, is beyond the scope of this article.

\section{Materialistic desire versus symbolic desire}

The same argument would also imply that it is not the desire to consume the product which motivates its purchase, but rather the desires to consume the cultural capital contained within the good.

\section{Social desire versus self desire}

The consumption of the cultural capital of Murphy's must of necessity take place in a social 
environment because there is a need for its observation so that the cultural capital can be transmitted from the product to user. This issue is highlighted in the Murphy's advertisements through the use of the county pub social atmosphere in the old advertisements and the more individualistic hyper-real situations in the new advertisements. The advertisements seem to reflect a change from social desire and interaction with friends to a more self focused desire and sexual interaction/ attraction.

\section{Real versus hyper-real}

One of the main contrasts between the old advertisements and the new, and therefore important devices to change the brand image, are the situations in which the actors find themselves. In the old advertisements the situations are real so that the actors simulate real life, whereas in the new advertisements the situations are unreal / hyper-real. This issue highlights the symbolic desire versus the materialistic. The recipients may also be encouraged to fantasise that they may meet the Sisters of Murphy's in real life. Thus they are taking part in the combination of opposites - the real with the unreal.

\section{Male power versus female power}

In speech, as opposed to written language, the formal structure of language is simpler and the rules are often broken, with meaning being partly given by contextual information as well as speech content. Thus it is possible for a conversation to be understood by all parties present but would be meaningless if written down and shown to a third party, because the vital contextual and implied content of the communication is missing. Halliday (1978) argues that the format of this code both determines social structure and is determined by such social structure and that the use of language socialises the child into the adult.

Linguistic studies have shown that language is used to identify social class (e.g. Labov, 1966, Klein, 1965, Hewitt, 1982) but that language also defines identity much more narrowly in terms of the social group to which one belongs. This view has been identified by Le Page (1968: 194) who stated:

'Each individual creates the systems for his verbal behaviour so that they shall resemble those of the group or groups with which from time to time he may wish to be identified'

Thus this view suggests that language acts like a membership card and assumes that language usage and behaviour is adopted to gain membership. A contrary argument from feminist discourse however suggests that language is used as a source of power and dominance, and used in this manner by the dominant group in order to exclude others. Thus Lakoff (1975: 136) considers language in the context of power and dominance, stating:

'The language of the favoured group, the group that holds the power, along with its non-linguistic behaviour, is generally adopted by the other group, not vice versa.'

Within the Murphy's advertisements the change in the brand image along this dialectic is exemplified within the old advertisements in which the males are dominant, whereas in the new advertisements females are dominant.

\section{Cool versus uncool}

This is a broad dialectic which subsumes some of the other dialectics covered in this paper. For example, the images associated with a country pub setting which in the context of Murphy's pervious advertisements can be regarded as 'uncool' by the new younger target audience, whereas the new advertisements portray a more active powerful images that may be 
regarded as more modern, hip and cool. For example, the 'cool' image is portrayed within the new advertisements when a young man is rescued by the Sisters of Murphy's from boring country singers. This situation is consistent with cool rebellion image where youth sees the old(er) generation as being 'uncool' and therefore wishes to conform to opposing lifestyles.

However other symbols of 'cool' such as the idealised consumption from a bottle or a can are missing.

\section{Old versus young}

Previously Murphy's had been advertised as a traditional product with a focus upon the traditional nature of Irish culture. As such the semiotic was one that would appeal to the older drinker whereas the larger market, at least in public houses, is that of the younger drinker. Arguably it is younger people who are more in need of cultural capital as it is they who need to seek self identity through reference to their peer group to a greater extent that do older people. People tend to acquire cultural capital with age, in the same way as they acquire economic capital, and so the desire for further acquisition suffers from diminishing returns with age. In this respect therefore a younger market segment is likely to be larger and more profitable that is an older market segment. In this respect therefore the cultural capital argument supports the economic consumption capability argument.

A attempted change in the brand image is achieved in the advertisements by the change in image from the traditional, slow social atmosphere of the country pub to the fashionable, active sexual imagery of the new advertisements.

\section{Country versus city}

This dialectic was considered by the company as being important for changing the image of the brand. The old advertisements were considered by the company as being too Irish and associated with county Ireland whereas they wished Murphy's to be associated with the dynamic "Celtic Tiger" image of city (Dublin) Ireland.

The dialects have raised important issues in connection with changing the image of this brand, which are generaliseable to the changing the image of any brand. While some dialectics may be brand specific and may only be applied to specific contexts, others plainly are not and are therefore more generaliseable to deconstruction of other advertising campaign. For example, the issues associated with the materialistic versus symbolic and the social versus the self may be applied elsewhere. Other dialects such as 'cool' versus 'uncool' and 'old' versus 'young' may also be appropriate to deconstruct the position of brands to a youth market and used as the basis of research into youth culture and their desires. Academic research into what youth cultures consider 'cool' is very limited (Crowther \& Combe, 2001). This is a field of research that needs addressing.

\section{THE SEMIOTIC STAGE}

The purpose of semiotic analysis therefore is to identify such purposes and to explore the interactions between the various actors and audiences for the communication event involving such corporate reporting. This semiotic analysis is based upon the premise that such interactions take place upon a stage, labelled the semiotic stage (Crowther, 2001), and that the advertising campaign can be considered to be the script which determines the interactions between the participants. Every script needs an author and in the context of this campaign it is clear that the authors of such scripts are primarily internal to the organisation. It is recognised that the services of external professionals, such as photographers, may be used in order to enhance the visual presentation but only within the control of internal members of 
the organisation. Although many people may be involved in the production of such a campaign it is clear that the ultimate editors of the script consist of the managers who will ensure that the finished text meets with their approval. Thus these managers, although acting in an editorial role, can be considered to be the authors of this script.

In a conventional view of advertising, time is considered in a linear manner so that the authors produce the script which is then presented to the audience. The audience, i.e. the readers of the script, in this linear depiction therefore have no involvement in the script but are merely passive recipients. This can be depicted thus:

\section{take in Figure 1}

According to this view there is merely a linear movement of the text from the authors to the audience. In this conventional view there is therefore no communication event but merely a script passed from one person to another. At the same time as the script is passed the burden of interpretation of the meaning of the script is also passed and this burden falls entirely upon the recipient to make of the script what he will.

A semiotic view of brand changing the brand image however takes a very different view and removes the linear constraint assumed within a traditional view of temporality. With this view the communication event is viewed as an interaction between the audience and the script but moreover as an interaction between the authors and the audience using the script as a mediating mechanism. These interactions take place upon what is defined here as the semiotic stage which encompasses the communication event. This stage can be depicted thus:

take in Figure 2

As far as the audience is concerned, just as for any other script, the authors cannot control the make up of that audience. Hence it becomes important for the script to be designed on the basis of appeal to a desired segment of that audience. The change in desired segment to which the script is to appeal provides the basis of the brand changing the brand image campaign. Interpreting the changing the brand image campaign event in the form of a script designed to appeal to an unknown audience increases its likeness to a cinema film script rather than to a play. In a film enactment there is no direct communication between the actors and the audience - the film is created in advance of audience receiving it, whereas in a play the script unfolds afresh at each enactment and the audience reaction can affect this unfolding. One of the essential differences between a film and a play is that in a film the narrative is provided in part as a series of snapshots of events which link together through the audience participation in the interpretation of the otherwise disjointed narrative (Carroll, 1980). This narrative provides a framework for the whole film in a symbolic form (Wright, 1975). This can be likened to the campaign where each individual component provides a series of snapshots of and the campaign, as a whole, provides a snapshot of the cultural value of the product in an atemporal sequence.

In many respects the nature of an advertising campaign makes for an unusual script because the primary actors are also the authors of the script while the other cast members also comprise the audience to the film. Metz (1974) identifies that a film script is aimed at the audience rather than the participants and in this case the script unfolds by aiming the script to the audience while also involving them in the script in minor roles.

\section{TRAVERSING THE SEMIOTIC STAGE}

Language consists simply of a system of differences (Saussure, 1966) and this led to his identification of the binary opposite of langue and parole. These were considered by Barthes (1967) as being synonymous with language and speech. This notion of binary opposition has 
however been extended into a binary opposition of scheme and usage (Hjelmslev, 1963). It is this notion of binary opposition which provides a mechanism for meaning construction, through categorisation, in the semiotic exploration of a text. This binary opposition provides a structure to the text and the construction of a text as an integral structure is tantamount to the recognition of its constituent pairs of binary opposites (Greimas, 1990). Furthermore what is important is not the binary opposites themselves but rather the meaning already existing within them (Greimas \& Rastier, 1968). Berger (1982) supports this notion of binary opposition as a means of discovering meaning within a text. He claims that the reading of a text semiotically implies an understanding of the binary opposites embedded within them, while Baudrillard (1988) regards the notion of binarism as an essential and sacred part of the text. The examination of binary opposites therefore provides a mechanism for traversing the semiotic stage and examining the communication event surrounding the text and its actors.

Although binary opposition is inherent in any text and the tensions existing within the text inevitably lead to one binarism being portrayed as good while the other is portrayed as bad, this portrayal is within the interpretation of the reader. Thus the task of the author is to shape the binarisms so that the pole intended by the author is accepted by the reader as the desirable pole of the opposition. It is argued that part of the semiotic is to present and continually reinforce the dialectics. This is achieved through the attempts to shape the readers interpretation of the binary oppositions inherent in the text. As stated earlier, the semiotics of changing the brand image effectively establishes a violent hierarchy of the poles of the dialectic such that a new position is established as good, whereas the old position, by implication becomes bad. This can be portrayed by the following model:

\section{take in Figure 3}

It needs to be recognised, however, that this attempt to establish the previous semiotic as bad - a necessary part of making the new semiotic desirable - has inherent within it the risk that the current consumers of the product will be alienated without the desired new consumers being attracted. This is represented in Figure 3 by the crossover arrows. Furthermore, the changing the brand image will only be successful if the attributes created in the semiotic are desired by the intended consumers. In the case of Murphy's beer it is suggested that this is problematic as changing the brand image seems to be aimed at positioning the product in competition with the designer drinks consumed by the young people for whom the semiotic has been created. Examples of such products would be designer lagers and ciders, or even alcopops, rather than the previously understood alternatives of Guinness and other beers. This re-positioning may be problematic for the company because it increases the potential competition considerably.

In conclusion, we suggest that the conceptualization of brand image as a 'narrative' and using a semiotic analysis to study this image provide insights for managers when attempting to change the image of a brand. We have argued that an understanding of the semiology of changing the brand image provides an effective method of ensuring that the interactive dialogue between the producer of a product and the consumer takes place in the manner desired by the producer. We have also discussed in this article, a model of changing brand image that may help managers understand this dialogue further. In this way advertising campaigns to change a brand image can become more effective. 


\section{Notes:}

1. The modern dialectic was created by Hegel (1956), whose motivation was to achieve understanding through the dialectic method (Findlay 1958). The Hegelian dialectic flows through history according to Hegel, who believed

that we each individually arise out of our past. Accordingly the thesis and antithesis of the dialectic also arise from the past and flow through history towards a resolution, but need not always be evident. Indeed it is argued that this axis of the dialectic can only become evident with hindsight but also that this recognition is necessary before any resolution can take place. Inherent in the exploration of the dialectic of brand image used in this article therefore is the development of an understanding of the thesis and antithesis, as a precursor to any consideration of the resolution of the dialectic. This dialectic method was subsequently adapted by Marx (see

Cornforth 1971) into dialectical materialism but the Kantian (1934) notion of a dialectic rather focuses upon the inherent contradictions in all scientific principles. It is this Kantian version of dialectics which is used in this article.

\section{REFERENCES}

Aaker, D. (1992), Managing Brand Equity, New York, The Free Press.

Askegaard, S. \& Ger, G. (1998) "Product-country images: towards a contextualised approach", in Englis, B. and Oolofsson, A. (eds.), European Advances in Consumer Research, Vol.111, Association for consumer Research, pp.50-58.

Bantz, C. R. (1993), Understanding Organizations: Interpreting Organizational Communication Cultures, University of South Carolina Press,

Barley, S. R. (1983) "Semiotics and the Study of Occupational and Organizational Cultures", Administrative Science Quarterly, No 28, 393-413.

Barthes, R. (1967), Elements of Semiology, trans A Lavers \& C Smith, New York, Noonday Press.

Barthes, R. (1973), Mythologies, trans A Lavers, London; HarperCollins.

Baudrillard, J. (1988), Selected Writings, edited and introduced by M. Poster, Cambridge, Polity Press.

Bauman, Z. (1990), Thinking Sociologically, London, Blackwell.

Belk, R.W. (1988) "Possessions and the Extended Self”, Journal of Consumer Research, Vol.15, September,pp.139-168.

Berger, A. A. (1982), Media Analysis Techniques, Newbury Park, Ca., Sage.

Bourdieu, P. (1984), Distinction: a social critique of the judgement of taste, trans R Nice, London, Routledge \& Kegan Paul.

Burrell, G. (1997), Pandemonium, London, Sage.

Carey, J. W. (1989), Communication as Culture: Essays on Media and Society, Routledge.

Carroll, J. M. (1980), Towards a structural psychology of cinema, The Hague; Mouton.

Christensen, L. T. \& Askegaard, S. (2001) "Corporate identity and corporate image revisited: A semiotic perspective”, European Journal of Marketing, Vol.35,No.3/4,pp.292-315.

Cleveland, C. E. (1986) "Semiotics: Determining What the Advertising Message Means to the Audience", In J. Olson and K. Sentis (Eds.), Advertising and Consumer Psychology, 
Vol.3, pp. 227-241, Praeger Publishers.

Cornforth M (1971), Dialectical Materialism, New York, Doubleday.

Cova, B. (1997) "'Community and Consumption - Towards a Definition of the "Linking Value" of Product or Services", European Journal of Marketing, Vol.31, Nos.3/4,pp.297-316.

Crowther, D. E. \& Combe, I. A., "Marketing 'Cool Brittania': Implications for

Organizations"; University of North London Studies in Social Marketing Series No 8, 2001

Crowther, D., (2002), A Social Critique of Corporate Reporting; London; Ashgate, (forthcoming)

Derrida J (1978), Writing and Difference, trans A Bass, London, Routledge \& Kegan Paul.

Douglas, M. \& Isherwood, B. (1980), The World of Goods: Towards an Anthropology of Consumption, Harmondsworth, Penguin.

Elliott, R. \& Wattanasuwan, K. (1998) "Brands as Symbolic Resources for the Construction of Identity", International Journal of Advertising, Vol. 17, No 2,pp.131-145.

Elliott, R. (1997) "Existential Consumption and Irrational Desire", European Journal of Marketing, Vol.31,Nos.3/4,pp.285-296.

Featherstone, M. (1991), Consumer Culture and Postmodernism, London, Sage.

Findlay, J. N. (1958), Hegel: a Re-examination, London; Allen \& Unwin

Firat, A.F. , Dholakia, N. \& Venkatesh, A. (1995) "Marketing in a Postmodern World", European Journal of Marketing, Vol.29, No.1,pp.40-56.

Graves, O. F., Flesher, D. L. \& Jordan, R. E. (1996) "Pictures and the bottom line: the television epistemology of U S annual reports", Accounting, Organizations and Society, Vol.21 No.1,pp.57-88.

Greimas, A. J. \& Rastier, F. (1968) "The interaction of semiotic constraints"; Yale French Studies, Vol.41,pp.86-105.

Greimas, A. J. (1990), The Social Sciences: A Semiotic View, Minneapolis, University of Minneapolis Press.

Guiraud P, (1975), Semiology, London, Routledge \& Kegan Paul.

Habermas, J. (1971), Knowledge and Human Interests, trans J J Shapiro, Boston, Mass., Beacon Press.

Halliday, M. A. K. (1978), Language as Social Semiotic, London; Edward Arnold.

Hegel, G. W. F. (1956), The Philosophy of History, New York, Dover Publications.

Hervey, S. (1982), Semiotic Perspectives, London, George Allen \& Unwin.

Hewitt, J. (1989) "White adolescent creole users and the politics of friendship", Journal of Multicultural and Multilingual Education, Vol.3,No.3.pp.340-357.

Hjelmslev, L. (1963), Prolegomena to a Theory of language, trans F J Whitfield, Madison, University of Wisconsin Press.

Kant, I. (1934), Critique of Pure Reason, London, Everyman

Kapferer, J. N. (1992), Strategic Brand Management, New York, The Free Press.

Keller, K. (1993) "Conceptualizing, measuring, and Managing customer-based brand equity", Journal of Marketing, Vol.57,pp.1-22. 
Kim, K. L. (1996), Caged in our own signs: a book about semiotics, Norwood, N.J., Ablex Publishing.

Klein, J. (1965), Samples from English Cultures, London, Routledge \& Kegan Paul.

Kotler, P. (1988), Marketing Management: Analysis, Planning and Control, NJ., PrenticeHall.

Labov, W. (1966) “The linguistic stratification of ' $r$ ' in New York City department stores”, in W. Labov, Sociolinguistic Patterns, Philadelphia, Pennsylvania University Press, 1966

Lacan, J. (1977), Ecrits: a selection, trans A Sheridan, London, Tavistock.

Laclan, E. (1990), New reflections on the Revolution of Our Time, London, Verso.

Lakoff, R. (1975), Language and Woman's Place, Cambridge, Harper \& Row.

Lash, S. \& Urry, J. (1994), Economies of Signs and Space, London, Sage.

Le Page, R. (1968) "Problems of description in multilingual communities", Transactions of the Philological Society, pp.189-212.

Meenaghan, T. (1995) “The role of advertising in brand image development”, Journal of Product \& Brand Management, Vol.4,No.4,pp.23-34.

Metz, C. (1974), Film Language: a Semiotics of the Cinema, Oxford, Oxford University Press.

Nava, M. (1997) "Women, the City and the Department Store", in P Falk \& C Campbell (Eds), The Shopping Experience, London, Sage.

Nebenzahl, I. D. \& Jaffe, E. D. (1996) Measuring the joint effect of brand and county image in consumer evaluation of global products, International Marketing Review,

Vol.13,No.4,pp.5-22.

Pierce, C. S. (1958) Collected papers Vol 5, eds P Weiss, C Hartshorne \& A Burks, Harvard, Harvard University Press.

Putnam, L. L., Philips, N. \& Chapman, P. (1996) Metaphors of Communication and Organization, In: S. R. Clegg, S. Hardy, and W. R. Nord, (Eds.), Handbook of Organizational Studies, Sage,pp.375-408.

Sapir E. (1949) The Unconscious Patterning of Behaviour in Society, in D G Mendelbaum (Ed), Selected Writings of Edward Sapir, Berkley, Ca., University of California Press.

Saussure, F de. (1966) Course in General Linguistics, trans W Baskin, New York, McGrawHill.

Thompson, C. J. , Pollio, H. R. \& Locander, W. B. (1994) The Spoken and the Unspoken: A Hermeneutic Approach to Understanding the Cultural Viewpoints that Underlie Consumers' Expressed Meanings, Journal of Consumer Research, Vol.21,pp.432-452.

Van Raaij, W. F. (1993) Postmodern Consumption, Journal of Economic Psychology, Vol.14,pp.541-563.

Veblen, T. (1970) The Theory of the Leisure Class, London, Unwin.

Wright, W. (1975) Six guns and society: a structural study of the Western, London, University of California Press. 


\section{Figures}

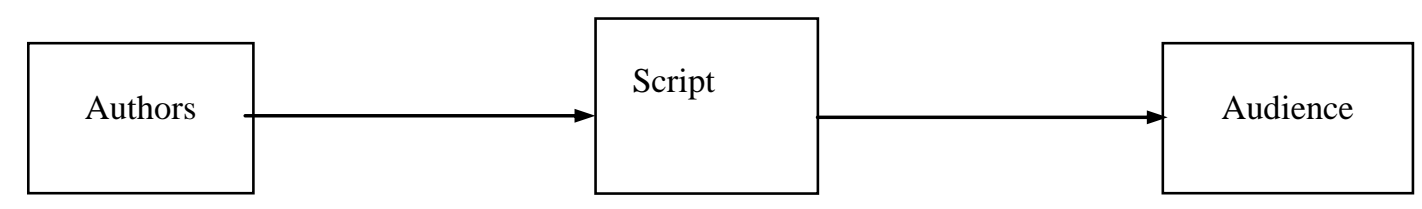

Figure 1 - A linear temporal view of advertising

The Semiotic Stage

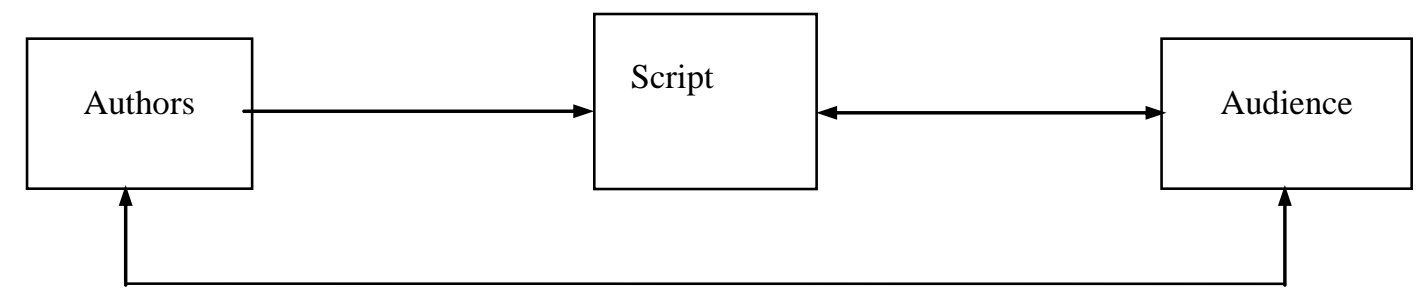

Figure 2 - An Interactive Temporal View of Advertising 


\section{Changing the Brand Image}

Move

Old Advertisement

New Advertisement

\begin{tabular}{|l|l|}
\hline \multicolumn{1}{|c|}{ Old Image (Bad) } \\
Materialistic consumption \\
$\begin{array}{l}\text { Self consumption } \\
\text { Materialistic desire } \\
\text { Social desire } \\
\text { Real } \\
\text { Male power } \\
\text { Uncool } \\
\text { Old } \\
\text { Country }\end{array}$
\end{tabular}

Figure 3 - A Model of the Semiology of Changing Brand Image 


\section{Plates}

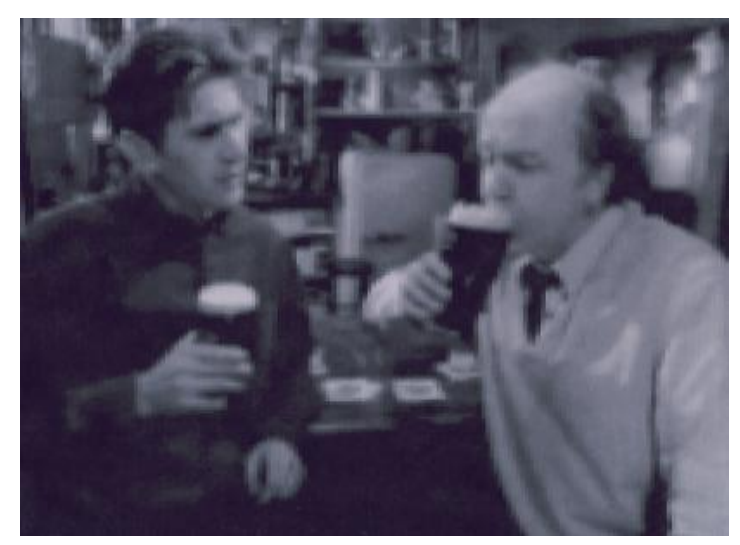

Plate 1 - The early campaign featuring the traditional Irish pub

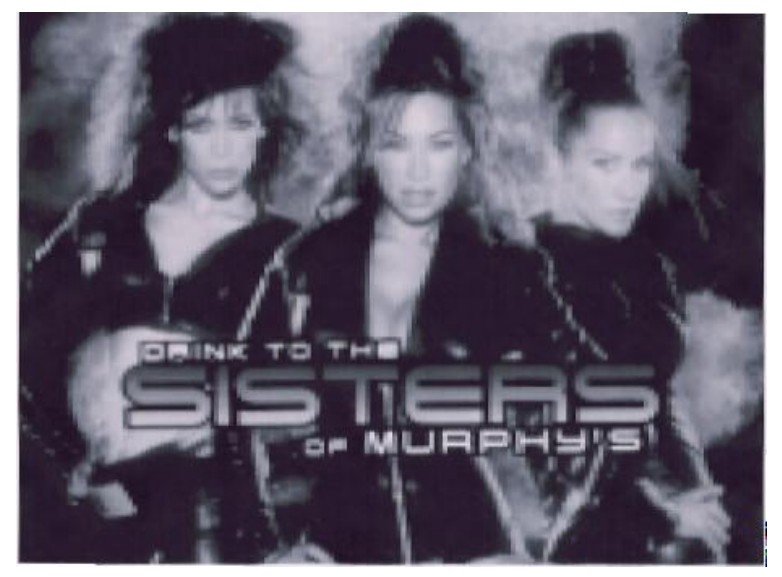

Plate 2 - The Sisters of Murphy from the new campaign 